\title{
Composite Lymphoma
}

National Cancer Institute

\section{Source}

National Cancer Institute. Composite Lymphoma. NCI Thesaurus. Code C38661.

Coexistence of Hodgkin and non-Hodgkin lymphoma in the same anatomic site. 